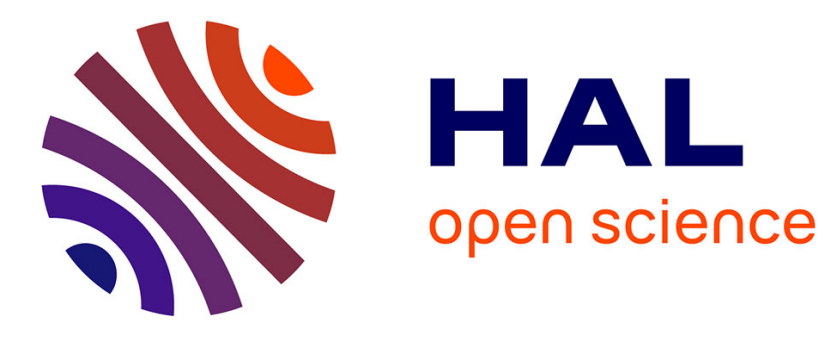

\title{
Aerobic catalytic systems inspired by copper amine oxidases
}

Martine Largeron

\section{To cite this version:}

Martine Largeron. Aerobic catalytic systems inspired by copper amine oxidases. Pure and Applied Chemistry, 2020, 92 (2), pp.233-242. 10.1515/pac-2019-0107 . hal-02995177

\section{HAL Id: hal-02995177 \\ https://hal.science/hal-02995177}

Submitted on 9 Nov 2020

HAL is a multi-disciplinary open access archive for the deposit and dissemination of scientific research documents, whether they are published or not. The documents may come from teaching and research institutions in France or abroad, or from public or private research centers.
L'archive ouverte pluridisciplinaire HAL, est destinée au dépôt et à la diffusion de documents scientifiques de niveau recherche, publiés ou non, émanant des établissements d'enseignement et de recherche français ou étrangers, des laboratoires publics ou privés. 


\title{
Conference paper
}

\section{Martine Largeron*}

\section{Aerobic catalytic systems inspired by copper amine oxidases}

https://doi.org/10.1515/pac-2019-0107

\begin{abstract}
The goal of sustainable development has been accepted as a common policy in current society. In response to this challenge, the development of green processes which utilize environmentally benign oxidants, reduce chemical waste and handling costs, is highly desirable. Given the widespread importance of imines as pivotal synthetic intermediates and essential pharmacophores in numerous biologically active compounds, various catalytic methods allowing the aerobic oxidation of amines to imines have been developed. Recently, noticeable progress has arisen from the discovery of various quinone-based catalytic systems, inspired by copper amine oxidase enzymes (CuAOs), which are able to reproduce the selectivity of CuAOs for primary amines and even to expand the amine substrates scope. However, the need for synthesizing these catalysts prior use adversely affects the economics as well as the eco-friendly nature of the method. To surpass these drawbacks, the "second-order" biomimicry idea has been recently advanced to describe a system in which in situ modification of pre-catalyst components affords the active biomimetic catalyst. This minireview especially covers our recent contribution to the design of bioinspired quinone-based catalysts for the aerobic oxidation of amines to imines which has culminated in a dual bioinspired protocol as an example of "second-order" biomimicry.
\end{abstract}

Keywords: aerobic oxidation; amine; bioinspired catalyst; imine; metalloenzyme; NICE-2018; purpurogallin; sustainable chemistry.

\section{Introduction}

Copper amine oxidases (CuAOs) are a family of metalloenzymes which couples the selective oxidation of primary amines to aldehydes with the reduction of dioxygen to hydrogen peroxide through the synergistic action of a quinone-based organic cofactor, 2,4,5-trihydroxyphenylalanine quinone or topaquinone (TPQ, 1) and a copper ion [1]. Although $\mathbf{1}$ is derived from a conserved tyrosine in a self-processing, post-translational event implicating the dual requirement for copper ion and molecular oxygen, it is now admitted that the oxidation of primary amine is mediated by $\mathbf{1}$ without direct involvement of the copper ion (Scheme 1) [2]. This might play a role in orienting the TPQ ring correctly in the active site and in facilitating the reduction of dioxygen to hydrogen peroxide [3]. Support for the transamination mechanism of CuAOs catalysis shown in Scheme 1 arises from a range of crystallographic, spectroscopic and kinetic probes over two decades [2-7]. The crucial step of the process is the conversion of the initial iminoquinone "Schiff base substrate" 2 to an

Article note: A collection of invited papers based on presentations at the The $4^{\text {th }}$ International Conference on Bioinspired and Biobased Chemistry \& Materials (NICE-2018), Nice, France, 14-17 October 2018.

*Corresponding author: Martine Largeron, UMR 8038 CNRS-Université Paris Descartes (Paris 5), Sorbonne Paris Cité, Faculté de Pharmacie de Paris, 4 avenue de l'Observatoire, 75270 Paris cedex 06, France, e-mail: martine.largeron@parisdescartes.fr. https://orcid.org/0000-0002-1725-8118 


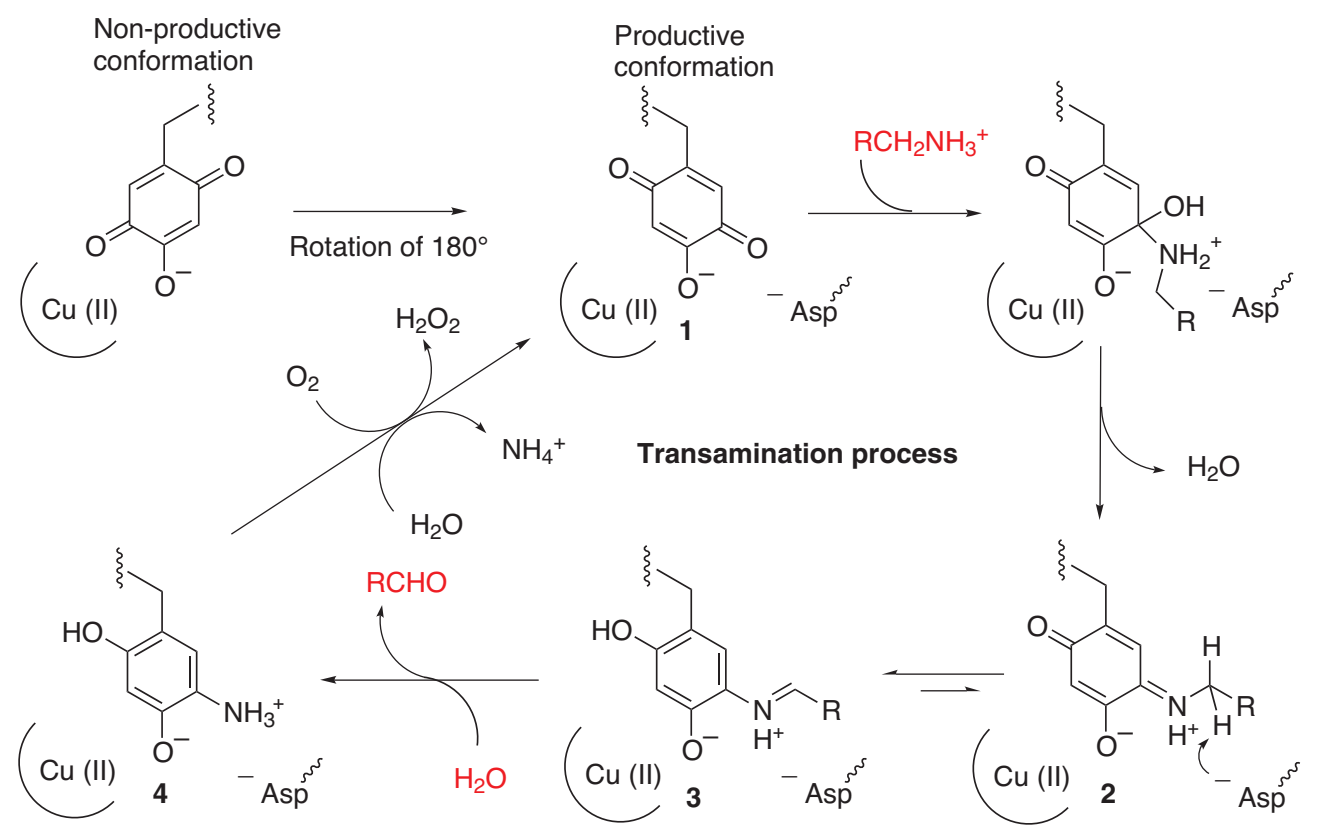

Scheme 1: Aerobic oxidation of primary amines mediated by topaquinone cofactor 1 . The transamination process takes place in the active site of CuAOs.

aminoquinol "Schiff-base product" 3, facilitated by abstraction of a proton from the $\alpha$-carbon of the amine substrate. A conserved aspartate side chain has been found to lie in close proximity to $\mathbf{1}$, thereby implicating this residue as the catalytic base for proton abstraction. Product aldehyde is then released by hydrolysis, generating the reduced cofactor aminoquinol 4, which must be recycled to the initial oxidized cofactor 1 to complete the catalytic cycle. Quinone models that mimic the active site of copper enzymes have also yielded important insights into the transamination process by which these metalloenzymes operate using benzylamine as the model substrate [8-13]. In organic media, the intermediate 3 can undergo a direct addition of benzylamine affording the homocoupled imine product $\mathrm{PhCH}=\mathrm{NCH}_{2} \mathrm{Ph}$ instead of the aldehyde formed in water. Due to the importance of imines as pivotal synthetic intermediates in a plethora of reactions and essential pharmacophores in various biologically active compounds, researchers have developed bioinspired quinone-based catalytic systems that use dioxygen, or, more preferably ambient air as the sole oxidant, with two objectives: first, to reproduce the activity and selectivity of CuAOs for unbranched primary amines; second, to expand the scope of amine substrates to alpha-branched primary amines, secondary amines and even tertiary amines including fused N-heterocycles [14-16]. This paper aims to provide a brief overview of this area which developed rapidly since 2012 by placing emphasis on our recent results.

\section{Bioinspired aerobic catalytic systems which reproduce the activity of CuAOs}

The organic chemists have found quinone-based small molecules able to reproduce the activity and selectivity of CuAOs for unbranched primary amines [17-19]. For example, Stahl and co-workers have shown that the tert-butyl analog of topaquinone $5(1.5 \mathrm{~mol} \%)$ acts as an efficient organocatalyst for the selective oxidation of primary benzylic amines to homocoupled imines, at room temperature under dioxygen atmosphere (Scheme 2) [20]. Oh and co-workers have described a cooperative catalytic system which utilizes 4-phenylo-naphthoquinone $6(2-5 \mathrm{~mol} \%)$ whose reactivity can be modulated through the nature of the cocatalyst. Using $\mathrm{Cu}(\mathrm{OAc})_{2}$ as the cocatalyst $(2-5 \mathrm{~mol} \%$ ), primary benzylic amines could be efficiently converted into 


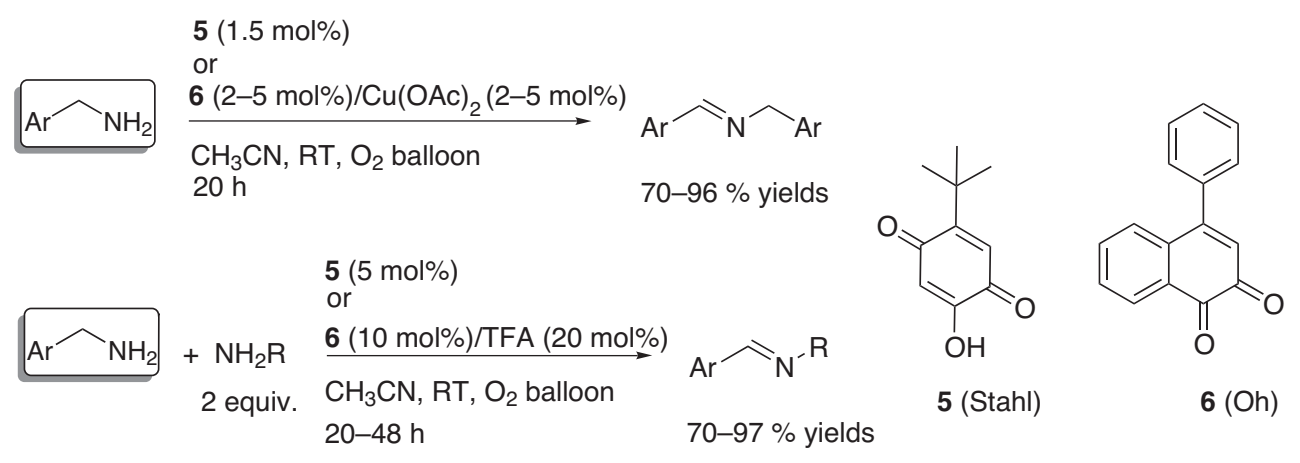

Scheme 2: Aerobic oxidation of benzylic primary amines mediated by quinone catalysts 5 and 6 .

homocoupled imines, at room temperature under dioxygen atmosphere [21]. The limitation of the reaction to primary benzylic amines allowed the preparation of cross-coupled imines by running the reaction in the presence of 2 equiv. of a second nonreactive primary amine. Upon increasing the catalyst loading to $5 \mathrm{~mol} \%$ for $\mathbf{5}$ and $10 \mathrm{~mol} \%$ for $\mathbf{6}$, cross-coupled products were formed with good to excellent selectivity. However, in the specific case of $\mathbf{6}$, the addition of TFA $(20 \mathrm{~mol} \%)$ as the cocatalyst was necessary to promote the crosscoupling reaction without any metal cocatalyst [21].

In this field, we have also described a bioinspired homogeneous cooperative catalytic system which is able to oxidize not only benzylic amines but also non-activated aliphatic primary amines at room temperature, under ambient air. The catalytic process combines two redox couples in a way reminiscent of CuAOs: the unstable ortho-iminoquinone organocatalyst $\mathbf{8}$, generated in situ from the corresponding ortho-aminoquinol $7(2 \mathrm{~mol} \%)$, is the substrate-selective catalyst, while the copper salt $(0.2 \mathrm{~mol} \%)$ serves as an electron transfer mediator by facilitating aerobic oxidation of 7 [22]. The oxidation process starts with atmospheric oxygen and continues in a cascade-like manner by passing the oxidation potential of dioxygen through the copper salt to the organic ortho-iminoquinone mediator $\mathbf{8}$, which finally oxidizes the amine substrate to the homo-coupled imine (Scheme 3).

The reaction mechanism is very close to the transamination process reported for natural CuAOs. Through the variation of the structure of the redox mediator $\mathbf{8}$, we showed that the catalytic process developed with electron-poor ortho-iminoquinone species bearing a 2-hydroxyl group. The presence of the active 2-hydroxyl group, which was engaged in an intramolecular hydrogen bond with the imine nitrogen to form a highly reactive Schiff base cyclic transition state (CTS) 9, constituted a prerequisite to the development of the catalytic process (Scheme 4). In the presence of a second amine $\mathbf{B}$, the homo-coupled imine was further alkylated by the amine $\mathbf{B}$ through a transimination pathway leading to the cross-coupled imine product [23]. Its formation could be driven by continuous oxidation of the extruded amine $\mathbf{A}$ which was re-engaged in the transamination

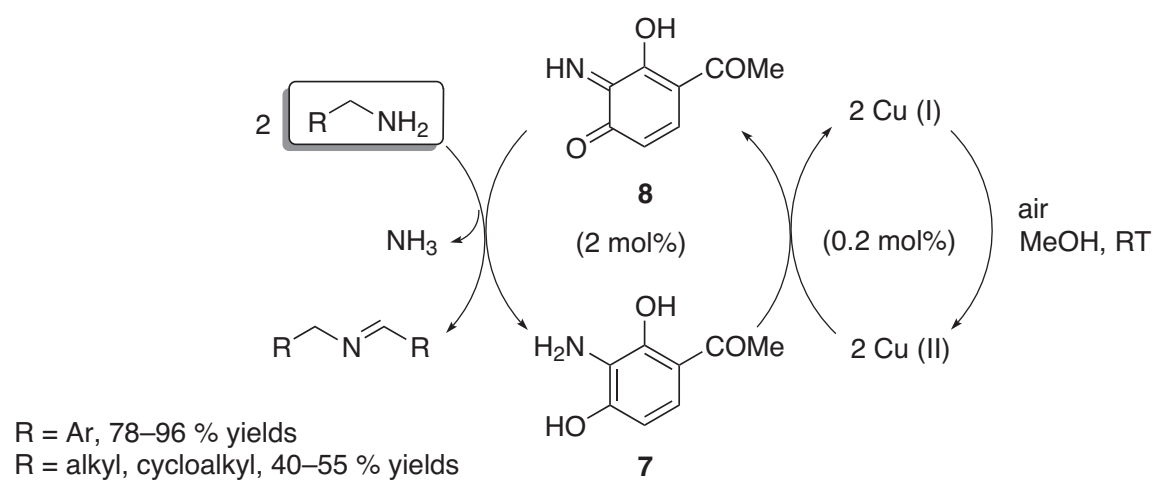

Scheme 3: Cu (II)/8-mediated aerobic oxidation of primary amines to imines. 


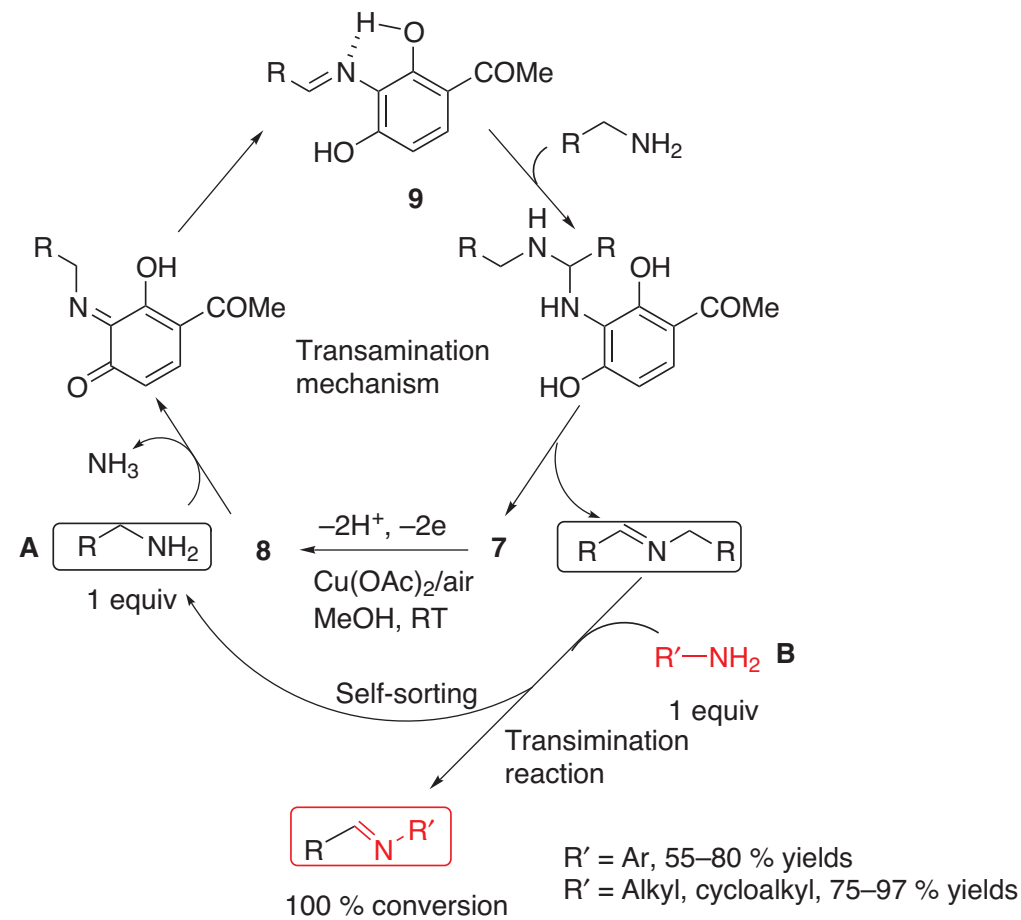

Scheme 4: Proposed ionic transamination/transimination pathway for the Cu (II)/8-mediated aerobic oxidative cross-coupling of primary amines.

mechanism. As a consequence, just one equivalent of each amine is sufficient to achieve exclusive formation of the cross-coupled imine product through a dynamic self-sorting process [24].

In subsequent studies, we showed that the mild reaction conditions required for the generation of unstable cross-coupled alkylimines could be useful for acting as intermediates for the preparation of medicinally interesting heterocycles such as functionalized benzimidazole derivatives, in the presence of $o$-aminoanilines B (Scheme 5) [25-27]. By heating the coupling reaction mixture at $45^{\circ} \mathrm{C}$ under air, in the presence of $4 \mathrm{~mol} \%$ of
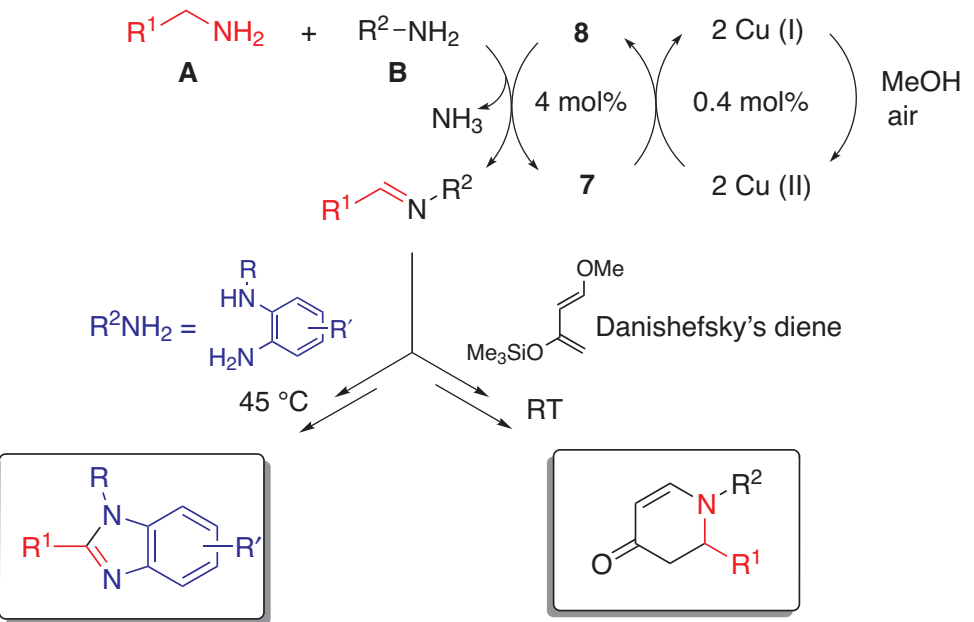

$\mathrm{R}^{1}=\mathrm{Ar}, 74-86 \%$ yields

$\mathrm{R}^{1}=\mathrm{Ar}, 80 \%$ yield

$\mathrm{R}^{1}=$ Alkyl, cycloalkyl, 45-75\% yields

$\mathrm{R}^{1}=$ cycloalkyl, $45 \%$ yield

Scheme 5: Synthetic applications involving unstable cross-coupled alkylimines generated in situ from the Cu (II)/8 co-catalytic system. 
7 and by using $\mathrm{CuBr}_{2}(0.4 \mathrm{~mol} \%)$ as the copper catalyst, a large molecular diversity could be attained through the variation of both coupling partners leading to 1,2-disubstituted benzimidazoles derivatives in good yields. Recently, Luo and co-workers have described the oxidative synthesis of heterocycles such as benzimidazoles, benzoxazoles and quinoxalines, which can be mediated by 4-methoxy-5-tert-butyl-o-quinone organocatalyst 10 (Scheme 6) without any metal cocatalysts [28]. At room temperature, the cross-coupled imines could also react in situ as a dienophile in Diels-Alder reactions with Danishefsky's diene to form the dihydro-4-pyridone derivatives (Scheme 5) [23].

This approach is interesting from the viewpoint of green chemistry because mild conditions are used, in particular ambient air as the oxidizing reagent, low reaction temperatures and low catalytic amounts of biocompatible copper salt and ortho-iminoquinone catalyst 8. In addition, the procedure is atom-economic, leaving ammonia as the sole by-product and tolerates large substrate scope including non-activated primary amines.

\section{Bioinspired aerobic catalytic systems which surpass the activity of CuAOs}

In the meantime, organic chemists have designed quinone-based catalytic systems capable of expanding the amine substrate scope. Alpha-branched primary amines are known to be poor substrates for the enzymes. The group of Luo [29] was the first to describe an effective ortho-quinone $\mathbf{1 0}$ as organocatalyst (10 mol\%) which operates at room temperature, under one atmosphere of dioxygen without any metal cocatalyst (Scheme 6), showing the higher performance of ortho-quinone $10 \mathrm{vs}$. para-quinone $\mathbf{1}$ in the aerobic oxidation of alphabranched primary amines. Ortho-naphthoquinone 6 (10 mol\%), described by Oh and co-workers for the oxidation of unbranched primary amines (Scheme 2), could also be used for the conversion of alpha-branched primary amines into imines [30]. However, whereas 10 promoted aerobic oxidation without any additives, the cooperative action of 6 and acetic acid (20 mol\%), together with the dehydrating effect of $3 \AA$ A molecular sieves, was necessary for the interruption of the oxidation reaction at the ketimine stage.

More challenging, the possibility to expand the scope to the oxidation of secondary amines, which function as inhibitors of TPQ through the formation of irreversible covalent adduct [31], was extensively explored. This reaction generally required the development of cooperative catalytic systems. For example, the group of Kobayashi [32] has described a cooperative heterogeneous catalytic system that consists of immobilized platinum/iridium bimetallic nanocluster catalyst $(0.5 \mathrm{~mol} \%)$ and 4-tert-butyl-o-quinone $\mathbf{1 1}$ as the redox active catalyst (15-50 mol\%) for the oxidation of secondary amines at $30^{\circ} \mathrm{C}$, under one atmosphere of dioxygen (Scheme 7). A slightly modified version of this protocol requiring the use of Rh nanoparticles (1 mol\%) anchored on carbon nanotubes (RhCNT) as co-catalyst, together with $\mathbf{1 1}(10 \mathrm{~mol} \%)$, was reported by Doris and coworkers. This catalytic system allowed the dehydrogenation of secondary amines including various nitrogen heterocycles under ambient air, at room temperature [33]. The group of Stahl has
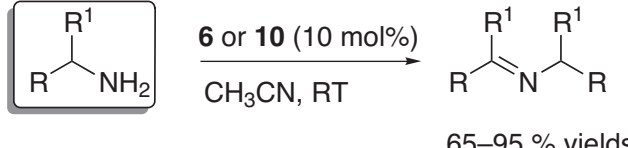

$65-95 \%$ yields<smiles>O=C1C=C(c2ccccc2)c2ccccc2C1=O</smiles>

Air, 24 h, $3 \AA$ MS $20 \mathrm{~mol} \% \mathrm{CH}_{3} \mathrm{CO}_{2} \mathrm{H}$

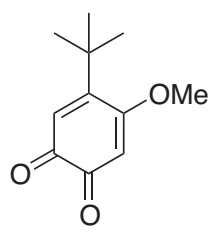

10 (Luo)

1 atm $\mathrm{O}_{2}, 48 \mathrm{~h}$

Scheme 6: Aerobic oxidation of alpha-branched primary amines mediated by organocatalysts 6 and 10 . 


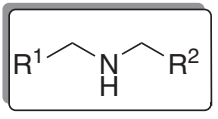

11 (15-50 mol\%)/Pt-Ir nanoclusters

$\mathrm{CHCl}_{3}: \mathrm{H}_{2} \mathrm{O}, 30^{\circ} \mathrm{C}$

$1 \mathrm{~atm} \mathrm{O}_{2}, 16 \mathrm{~h}$

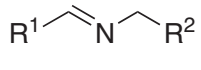

$72-90 \%$ yields<smiles>CC(C)(C)C1=CC(=O)C(=O)C=C1</smiles>

11 (Kobayashi)

11 (10 mol\%)/RhCNT nanohybrid<smiles>C1=CC2=C(C=[I+]1)NCCC2</smiles>
$\mathrm{CHCl}_{3}: \mathrm{H}_{2} \mathrm{O}, \mathrm{RT}$, air, $10 \mathrm{~h}$ (Doris)

12 as octahedral $\left[R u(p h d)_{3}\right]^{2+}(2.5 \mathrm{~mol} \%)$ with $5 \mathrm{~mol} \% \mathrm{Co}$ (salophen), $\mathrm{CH}_{3} \mathrm{CN}, \mathrm{RT}$, air, $48 \mathrm{~h}$

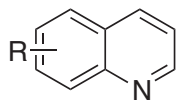

$60-98 \%$ yields

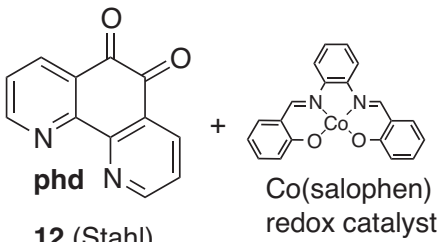

$10(10 \mathrm{~mol} \%)$

$\mathrm{CH}_{3} \mathrm{CN}, 60^{\circ} \mathrm{C}, 1$ atm $\mathrm{O}_{2}, 48 \mathrm{~h}$

6 (10 mol\%)/ $\mathrm{Ag}_{2} \mathrm{CO}_{3}$ (20 mol\%)

$\mathrm{CH}_{3} \mathrm{CN}, \mathrm{RT}, 1$ atm $\mathrm{O}_{2}, 36 \mathrm{~h}$<smiles></smiles>

$\mathrm{R}^{1}$

CH,

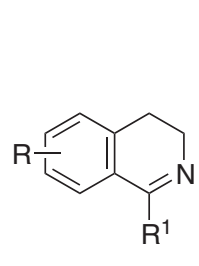

$86-98 \%$ yields<smiles>O=C1C=C(c2ccccc2)c2ccccc2C1=O</smiles>

$6(\mathrm{Oh})$<smiles>COC1=CC(=O)C(=O)C=C1C(C)(C)C</smiles>

10 (Luo)

Scheme 7: Aerobic oxidation of secondary amines including fused N-heterocycles mediated by organocatalyst 6 and cooperative catalytic systems.

shown that the ruthenium/1,10-phenantroline-5,6-dione (phd) 12 complex catalyst ( $2.5 \mathrm{~mol} \%$ ), in combination with Cobalt (salophen) as a redox catalyst ( $5 \mathrm{~mol} \%$ ) allowed the oxidation of tetrahydroquinolines to quinolines under ambient conditions [34]. Furthermore, they have brought definitive evidence for a nonbiomimetic addition-elimination pathway involving a hemiaminal intermediate, which was characterized by NMR spectroscopy [35]. $O$-naphthoquinone $6(10 \mathrm{~mol} \%)$ was also able to dehydrogenate some fused $\mathrm{N}$-heterocycles such as tetrahydroisoquinoline and 9,10-dihydroacridine, at room temperature with the assistance of $\mathrm{Ag}_{2} \mathrm{CO}_{3}(20 \mathrm{~mol} \%)$ as a cocatalyst [21]. Finally, o-quinone 10 (10 mol\%) was capable to promote the oxidation of tetrahydroisoquinolines to dihydroisoquinolines at more elevated temperature $\left(60^{\circ} \mathrm{C}\right)$, but without any additives [29].

Beyond the established reactivity of bioinspired catalytic systems with primary and secondary amines, the quinone-catalyzed aerobic oxidation of tertiary amines remained a challenge. Only, Stahl and co-workers had reported the oxidation of $\mathrm{N}$-methylindoline in acetonitrile mediated by $\mathbf{1 2}$ as octahedral $\left[\mathrm{Ru}(\mathrm{phd})_{3}\right]^{2+}$ complex (5 mol\%) in combination with $\mathrm{ZnI}_{2}(1 \mathrm{~mol} \%)$ as the co-catalyst [35]. However, the yield was limited to $48 \%$ whereas electron-deficient $\mathrm{N}$-tosylindoline could not be oxidized under the same experimental conditions. Stahl and co-workers have just demonstrated that their $\left[\mathrm{Ru}(\mathrm{phd})_{3}\right]^{2+}$ complex $(2.5 \mathrm{~mol} \%)$ is effective for the aerobic dehydrogenation of substituted indolines, provided the reaction is conducted in methanol, at $40^{\circ} \mathrm{C}$, in the presence of $5 \mathrm{~mol} \%$ of Co(salophen) as an electron-transfer mediator (Scheme 8). The utility of the protocol has been proved in the preparation of pharmaceutical intermediates [36]. In the same vein, Luo and co-workers have reported the high efficiency of their o-quinone 10 (10 mol\%) in tertiary amine dehydrogenation reactions [16, 37]. Especially, cross-dehydrogenative-coupling reactions of $\mathrm{N}$-aryl tetrahydroisoquinoline derivatives were performed in the presence of various nucleophiles ( 2 equiv.), at $60^{\circ} \mathrm{C}$, under aerobic neat conditions. Functionalization adjacent to the nitrogen atom could be obtained in high yields with nitroalkanes, dialkyl malonates, dialkylphosphonates, indoles and even ketones [37]. Finally, $o$-quinone 10 was found to be the only bioinspired organocatalyst able to oxidize the three classes of amines.

In summary, CuAOs have constituted a rich source of inspiration for the rational design of synthetic catalysts for the oxidation of amines to imines. Some catalysts are now able to reproduce the activity and selectivity for unbranched primary amines including non-activated native substrates for CuAOs, while others surpass the activity of CuAOs by expanding the substrate scope to alpha-branched primary amines, 


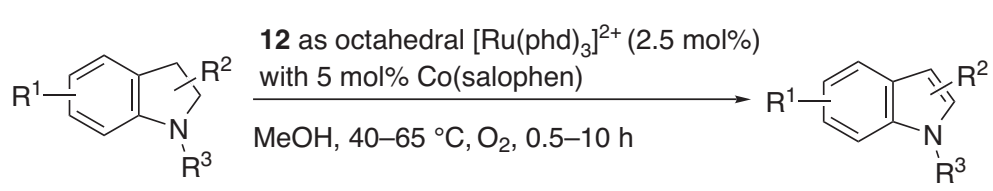

$60-95 \%$ yields

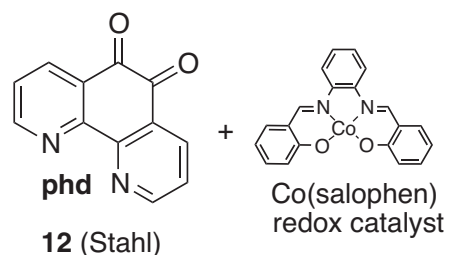

12 (Stahl)

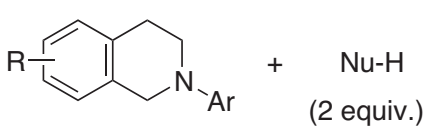

$\frac{6(10 \mathrm{~mol} \%)}{60{ }^{\circ} \mathrm{C}, 1 \text { atm } \mathrm{O}_{2}, 12-24 \mathrm{~h}}$

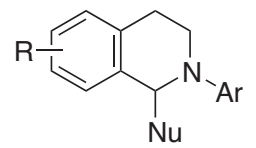

$60-90 \%$ yields

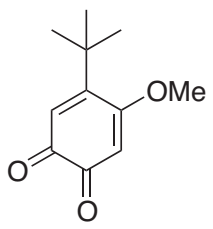

10 (Luo)

Scheme 8: Aerobic oxidation of tertiary amines and cross-dehydrogenative coupling reactions mediated by organocatalyst 10 and cooperative catalytic system $12 / \mathrm{Co}$ (salophen).

secondary amines and even tertiary amines. However, the procedures suffer still some drawbacks: first, the contamination of the final products by metal residues may constitute a problem in the synthesis of medicinally relevant compounds. Second, the majority of bioinspired catalysts has to be synthesized prior use affecting the economics as well as the eco-friendly nature of the methods. Therefore, the use of a commercially available inexpensive starting material working without any additives would be welcome to limit the production of waste. Unfortunately, commercially available quinone-based catalysts reminiscent of TPQ 1 are not sufficiently reactive to promote the aerobic oxidation of non-activated amines without any additives. New prospects are briefly presented in the last part of this review.

\section{A dual bioinspired protocol as an example of "second-order biomimicry"}

Recently, the "second-order" biomimicry concept has been proposed to describe a system in which in situ modification or processing of precatalyst components affords the active biomimetic catalyst [38], as opposed to "first-order" biomimicry in which the active bioinspired catalyst is synthesized directly. Stahl and co-workers have illustrated this concept through the aerobic oxidation of alcohols to aldehydes. They have demonstrated that $\mathrm{N}, \mathrm{N}^{\prime}$-di-tert-butylethylenediamine can serve as a precatalyst which undergoes an in situ oxidative self-processing step reminiscent of copper oxygenase enzymes affording the corresponding nitroxyl (Scheme 9). This can further act as the active cocatalyst that promotes, in cooperation with a copper salt, efficient aerobic alcohol oxidation in a way that mimics the activity of galactose oxidase. The protocol allows the in situ generation of highly reactive nitroxyl derivative which is not readily prepared or isolated due to its rapid decomposition.

This new concept allows a more profound relationship between synthetic and naturally occurring catalytic systems. As TPQ cofactor 1 is formed via post-translational modifications of CuAOs active sites, recently, we have thought that this "second-order" biomimetic strategy could be applied to the development of bioinspired catalysts for the selective aerobic oxidation of primary amines to imines. At the starting point of our investigations, we have been drawn to the planar structure of natural purpurogallin (2,3,4,6-tetrahydroxy$5 H$-benzocyclohepten-5-one) $\mathbf{1 3}$ as a potential precursor of a highly reactive $o$-quinone-based organocatalyst 14 (Scheme 10). As for $\mathbf{1}$ and 8, purpurogallin 13 showed an active hydroxyl group at the 4-position which allowed the formation of a highly reactive H-bonded CTS 15 under single turnover. This facilitated the development of the transamination mechanism which engaged the active $o$-iminoquinone organocatalyst 17 without the need to regenerate 14. Interestingly, the catalytic process developed without the need of additional copper salt as a cocatalyst. 


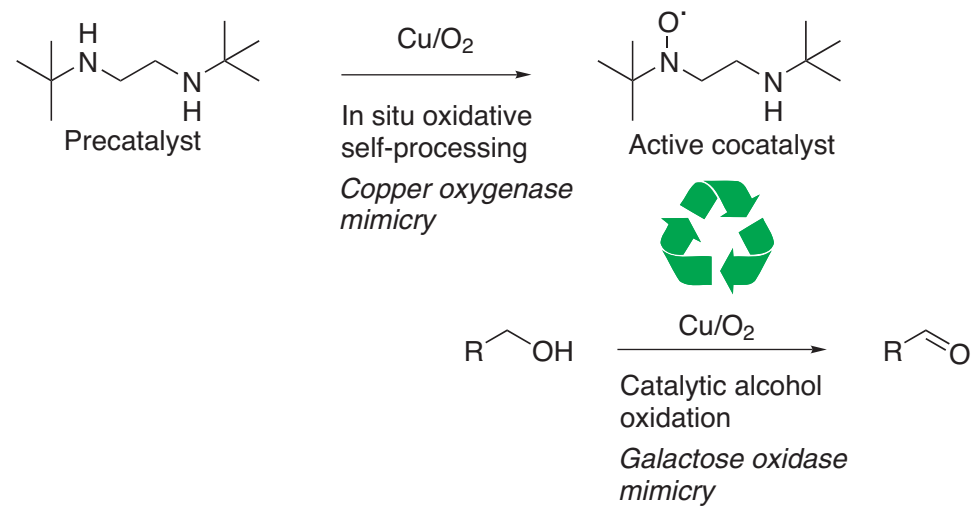

Scheme 9: Second-order biomimicry for the catalytic oxidation of alcohols to aldehydes.<smiles>O=c1c(O)cccc2cc(O)c(O)c(O)c12</smiles>

13

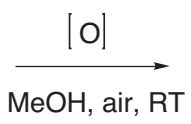

Single turnover<smiles>Nc1c(O)cc2cccc(O)c(=O)c2c1O</smiles>

16

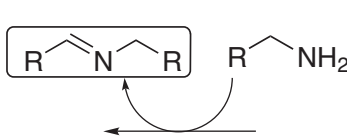

Transamination mechanism<smiles>[R]C=[N+]1[CH]Oc2c(c(O)cc3cccc(O)c(=O)c23)O1</smiles>

15<smiles>CC(=O)C1=C(O)C(=N)C(=O)C=C1Br</smiles><smiles>N=C1C=c2cccc(O)c(=O)c2=C(O)C1=O</smiles><smiles>[R]C1C(CN)CC2CCCC1C2C</smiles>

Scheme 10: Aerobic oxidation of primary amines to imines mediated by the $o$-iminoquinone active organocatalyst 17.

However, the limited availability of natural purpurogallin 13 led us to concentrate on its well-established biosynthesis which involves the oxidative dimerization of pyrogallol 19 generated from gallic acid 18 [39, 40]. Two molecules of ortho-quinone react through a [5+2] cycloaddition reaction followed by tautomerization to afford the benzotropolone scaffold 20 (Scheme 11). This intermediate leads to purpurogallin after nucleophilic attack by water, decarboxylation and oxidation steps.

Using pyrogallol 19 as the starting material, we have then developed a one-pot cascade reaction that mimics both purpurogallin biosynthesis (Scheme 11) and copper amine oxidase activity [41]. The reaction sequence uses inexpensive commercially available pyrogallol 19 as a precatalyst $(8 \mathrm{~mol} \%)$ and allows in situ formation of not easily accessible purpurogallin 13. This is further engaged in the CuAOs-like catalytic process for producing, under single turnover, the active biomimetic organocatalyst 17 which mediates the oxidative coupling of primary amines to imines under mild conditions (Scheme 12). Without any metal cocatalyst, this new protocol gives also access to 1,2-disubstituted benzimidazole derivatives, when $o$-aminoanilines are used as amine $\mathrm{R}^{\prime}-\mathrm{NH}_{2}$ [41]. 
<smiles>CC(=O)OCC(=O)O</smiles>

18<smiles>O=c1c(O)cccc2cc(O)c(O)c(O)c12</smiles>

13<smiles>Oc1cccc(O)c1O</smiles>

19

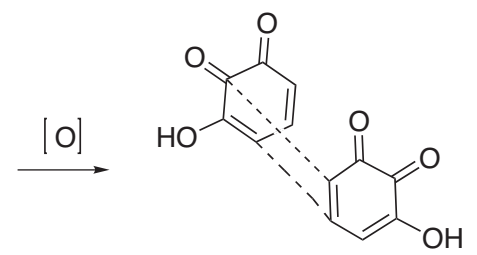

$$
\begin{gathered}
{[5+2] \text { cycloaddition }} \\
\text { tautomerization }
\end{gathered}
$$<smiles>CC(C)CO</smiles><smiles>O=C1C=CC2OC1c1cc(O)c(O)c(O)c1C2O</smiles>

Scheme 11: Established biosynthesis of Purpurogallin 13 from gallic acid.<smiles>Oc1cccc(O)c1O</smiles>

(8 $\mathrm{mol} \%)$

Inexpensive commercially available precatalyst

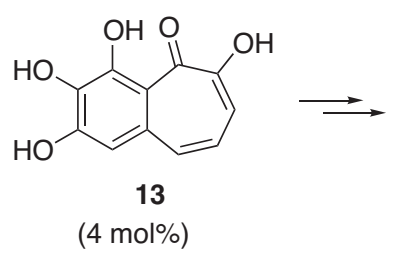<smiles>N=C1C(=O)C=c2cccc(O)c(=O)c2=C1O</smiles>

17 organocatalyst

$$
\begin{aligned}
& \mathrm{R}^{\prime}=\text { alkyl, cycloalkyl, } 80-93 \% \text { yields } \\
& \mathrm{R}^{\prime}=\text { aryl, } 55 \% \text { yield }
\end{aligned}
$$

Scheme 12: Example of "Second-order" biomimicry for the oxidative cross-coupling of primary amines to imines.

Finally, this dual bioinspired protocol, which utilizes inexpensive commercially available pyrogallol precatalyst for generating the active biomimetic organocatalyst in situ, constitutes an appropriate illustration of the potential of "second order biomimicry", in terms of atom economy while preserving the benefit of the eco-friendly nature of the bioinspired catalytic processes.

\section{Conclusion}

Due to the prevalence of imines as pivotal intermediates in the synthesis of fine chemicals and pharmaceuticals, tremendous research efforts have been made for developing CuAOs-like biomimetic catalytic systems for the aerobic oxidation of amines to imines, based on the utilization of environmentally benign oxidants. Through "first-order" biomimicry, synthetic catalysts have significantly increased the substrate scope of CuAOs allowing the oxidation of alpha-branched primary amines, secondary amines and even tertiary amines. On other side, "second-order biomimicry" has led to the utilization of pyrogallol as an inexpensive commercially available precursor of an active $o$-iminoquinone organocatalyst able to reproduce the activity and selectivity of $\mathrm{CuAOs}$ for the native non-activated primary amine substrates. Although numerous proteinaceous cofactors are post-translationally derived from encoded amino acids, surprisingly, "second-order" biomimicry is not typically considered in the design or development of bioinspired catalysts. A rational 
application of this concept should allow the discovery of efficient catalysts generated from simple, low-cost precursors introducing new opportunities in the future.

\section{References}

[1] S. M. Janes, D. Mu, D. Wemmer, A. J. Smith, S. Kaur, D. Maltby, A. L. Burlingame, J. P. Klinman. Science 248, 981 (1990).

[2] J. P. Klinman, F. Bonnot. Chem. Rev. 114, 4343 (2014).

[3] Q. Su, J. P. Klinman. Biochemistry 37, 12513 (1998).

[4] J. P. Klinman. Chem. Rev. 96, 2541 (1996).

[5] N. M. Okeley, W. A. van der Donk. Chem. Biol. 7, R159 (2000).

[6] M. Mure, S. A. Mills, J. P. Klinman. Biochemistry 41, 9269 (2002).

[7] G. A. Juda, E. M. Shepard, B. O. Elmore, D. M. Dooley. Biochemistry 45, 8788 (2006).

[8] Y. Lee, L. M. Sayre. J. Am. Chem. Soc. 117, 3096 (1995).

[9] M. Mure, J. P. Klinman. J. Am. Chem. Soc. 117, 8698 (1995).

[10] M. Mure, J. P. Klinman. J. Am. Chem. Soc. 117, 8707 (1995).

[11] Y. Lee, L. M. Sayre. J. Am. Chem. Soc. 117, 11823 (1995).

[12] K. Q. Ling, J. Kim, L. M. Sayre. J. Am. Chem. Soc. 123, 9606 (2001).

[13] M. Mure, S. X. Wang, J. P. Klinman. J. Am. Chem. Soc. 125, 6113 (2003).

[14] A. E. Wendlandt, S. S. Stahl. Angew. Chem. Int. Ed. 54, 14638 (2015).

[15] M. Largeron. Org. Biomol. Chem. 15, 4722 (2017).

[16] R. Zhang, S. Luo. Chin. Chem. Lett. 29, 1193 (2018).

[17] M. Largeron, M.-B. Fleury. Science 339, 43 (2013).

[18] D. V. Jawale, E. Gravel, E. Villemin, N. Shah, V. Geersten, I. N. N. Namboothiri, E. Doris. Chem. Commun. 50, 15251 (2014).

[19] A. T. Murray, R. King, J. V. G. Donnelly, M. J. H. Dowley, F. Tuna, D. Sells, M. P. John, D. R. Carbery. Chem CatChem 8, 510 (2016).

[20] A. E. Wendlandt, S. S. Stahl. Org. Lett. 14, 2850 (2012).

[21] Y. Goriya, H. Y. Kim, K. Oh. Org. Lett. 18, 5174 (2016).

[22] M. Largeron, M.-B. Fleury. Angew. Chem. Int. Ed. 51, 5409 (2012).

[23] M. Largeron, M.-B. Fleury. Chem. Eur. J. 21, 3815 (2015).

[24] M. E. Belowich, J. F. Stoddart. Chem. Soc. Rev. 41, 2003 (2012).

[25] K. M. H. Nguyen, M. Largeron. Chem. Eur. J. 21, 12606 (2015).

[26] K. M. H. Nguyen, M. Largeron. Eur. J. Org. Chem. 2016, 1025 (2016).

[27] K. M. H. Nguyen, M. Largeron. Synthesis 50, 241 (2018).

[28] R. Zhang, Y. Qin, L. Zhang, S. Luo. Org. Lett. 19, 5629 (2017).

[29] Y. Qin, L. Zhang, J. Lv, S. Luo, J. P. Cheng. Org. Lett. 17, 1469 (2015).

[30] G. Golime, G. Bogonda, H. Y. Kim, K. Oh. ACS Catal. 8, 4986 (2018).

[31] Y. Zhang, C. Ran, G. Zhou, L. M. Sayre. Bioorg. Med. Chem. 15, 1868 (2007).

[32] H. Yuan, W.-J. Yoo, H. Miyamura, S. Kobayashi. J. Am. Chem. Soc. 134, 13970 (2012).

[33] D. V. Jawale, E. Gravel, N. Shah, V. Dauvois, H. Li, I. N. N. Namboothiri, E. Doris. Chem. Eur. J. 21, 7039 (2015).

[34] A. E. Wendlandt, S. S. Stahl. J. Am. Chem. Soc. 136, 11910 (2014).

[35] A. E. Wendlandt, S. S. Stahl. J. Am. Chem. Soc. 136, 506 (2014).

[36] B. Li, A. E. Wendlandt, S. S. Stahl. Org. Lett. 21, 1176 (2019).

[37] R. Zhang, Y. Qin, L. Zhang, S. Luo. J. Org. Chem. 84, 2542 (2019).

[38] S. D. McCann, J.-P. Lumb, B. A. Arndtsen, S. S. Stahl. ACS Cent. Sci. 3, 314 (2017).

[39] W. Dürckheimer, E. F. Paulus. Angew. Chem. Int. Ed. 24, 224 (1985).

[40] P. Ellerbrock, N. Armanino, M. K. Ilg, R. Webster, D. Trauner. Nat. Chem. 7, 879 (2015).

[41] M. Largeron, M.-B. Fleury. Chem. Eur. J. 23, 6763 (2017). 